\title{
REACTION DYNAMICS OF ELECTRONICALLY EXCITED BARIUM ATOMS WITH FREE MOLECULES AND MOLECULAR CLUSTERS
}

\author{
J. M. MESTDAGH, C. ALCARAZ, J. BERLANDE, J. CUVELLIER, \\ T. GUSTAVSSON, P. MEYNADIER, P. de PUJO, \\ O. SUBLEMONTIER and J. P. VISTICOT
}

\author{
Service de Physique des Atomes et des Surfaces, Centre d'Etudes Nucléaires \\ de Saclay, 91191 Gif-sur-Yvette Cedex, France
}

(Received 23 March, 1990; accepted 15 April, 1990)

In this review article we describe some recent results obtained in our laboratory. The successful combination of crossed molecular beam techniques and various laser excitation schemes has been used to study chemiluminescent reactions of ground and excited electronic states of barium with free molecules and molecular clusters. Studies include the identification of reaction products in cases where many chemiluminescent reaction channels are opened. The case of $\mathrm{Ba}\left(6 s 6 p^{1} P_{1}, 6 s 5 d^{1} D_{2}, 6 s 5 d^{3} D_{\mathrm{i}}\right)$ reacting with $\mathrm{H}_{2} \mathrm{O}$, methanol, ethanol, propanol-1, propanol-2, methyl-2, propanol-2, butanol-1, allyl alcohol, dimethyl ether, diethyl ether and diallyl ether is examined. A reaction mechanism is proposed which accounts for all these reactions. Studies reported in this review also include the unravelling of reaction dynamics where various forms of energy are mixed (electronic and kinetic energy). This is shown in studies of $\mathrm{Ba}\left({ }^{1} D_{2}\right.$ and $\left.{ }^{1} P_{1}\right)+\mathrm{O}_{2}$ reactions. Finally the role of molecular clusters as reactant is examined. Evidence is provided that clusters of $\mathrm{N}_{2} \mathrm{O}, \mathrm{H}_{2} \mathrm{O}$ and $\mathrm{CO}_{2}$, in collision with $\mathrm{Ba}\left({ }^{1} S_{0}\right.$, and $\left.{ }^{1} P_{1}\right)$, do not lead efficiently to both reactive and non reactive luminescent exit channels.

KEY WORDS: Ba, chemiluminescence, crossed beam, molecular clusters, alkyl alcohols, $\mathrm{O}_{2}, \mathrm{H}_{2} \mathrm{O}$, allyl alcohol.

\section{INTRODUCTION}

Reactions of ground state alkaline earth atoms with oxygenated compounds have led to many studies during the seventies that are reviewed in Ref. 1. In particular, the detailed reaction dynamics of several reactant pairs has been investigated using crossed molecular beam or beam/gas equipments operating under the single collision regime. ${ }^{1}$ Since the late seventies, this field has moved towards more unusual situations. The first research direction is to investigate the reactivity of electronically excited alkaline earth atoms. ${ }^{2-7}$ This very interesting field is rapidly growing since it is believed to bring new forms of reactivity for the alkaline earth atoms. As is well known indeed in photochemistry, the electronic excitation offers a unique possibility of changing the energy and symmetry of the valence electrons that participate to the reaction. This field profits also by the rapid advancement of laser technology and by the fruitful combination of crossed molecular beam and laser techniques. The second research direction is linked to the exploding amount of works devoted to cluster physics. It concerns the reactivity of ground state and excited state alkaline earth 
atoms with molecular clusters. ${ }^{8-12}$ The interest of these studies is that molecular clusters may be considered as allowing for reaction dynamics studies in a solvated environment.

Over the past two years, this laboratory has been examining these situations using an apparatus which combines three techniques: crossed molecular beams, cw laser excitation and optical detection. The possibilities offered by the apparatus are reviewed in Section II together with a short description of the experimental setup. The paper then reviews some of the recent work performed in this laboratory. This concerns reactions of excited state barium with free molecules $\mathrm{O}_{2}, \mathrm{H}_{2} \mathrm{O}$ and various organic molecules (Section III), and reactions of ground state and excited state barium with molecular clusters $\mathrm{N}_{2} \mathrm{O}, \mathrm{CO}_{2}$ and $\mathrm{H}_{2} \mathrm{O}$ (section IV).

\section{EXPERIMENT}

The crossed beam machine and the techniques used for data acquisition and analysis have been described extensively in our former publications..$^{5,12,13,14}$

Various types of experiments can be performed with this machine.

i) Analysis of chemiluminescence spectra resulting from reactive collisions as a function of the collision energy over a wide range extending between 0.1 and $1 \mathrm{eV}$. This is the main topic of the review.

ii) Laser induced detection of non luminescent reaction products. A preliminary result is shown here for the $\mathrm{Ba}\left(6 s 5 d^{1} D_{2}\right)+\mathrm{H}_{2} \mathrm{O}$ reaction.

iii) Total cross section measurements of reactive and non reactive luminescent processes as a function of the collision energy. Collisionally induced inelastic energy transfers to the $6 s 6 p^{3} P_{1}$ level of barium are reported here.

iv) Differential cross section measurements as a function of the collision energy for non reactive processes. Laser induced fluorescence is combined with Doppler profile analysis for this purpose. (Not reported here, see Ref. 15).

v) Studies of polarization effects in collision processes. (Not reported here, see Ref. 15).

The number of reactant pairs that can be studied with this machine is very large. The primary beam can operate with any alkaline or alkaline earth metal atoms. The secondary beam can support experiments with any reagent that is gaseous or liquid at room temperature. The only true limitation is that the reaction product must be either luminescent or suitable for laser induced chemiluminescence detection.

For the experiments reported below on excited barium atoms in reactions, the electronic excitation of $\mathrm{Ba}$ was performed by $\mathrm{cw}$ laser excitation with the laser tuned to the barium resonance line at $553 \mathrm{~nm}$. Two excitation schemes were used. The first one is with the laser crossing the barium beam upstream of the reaction zone. Because of the optical pumping cycles schemed in Figure 1, most of the barium atoms are transferred radiatively to the metastable levels $6 s 5 d^{1} D_{2}$ and $6 s 5 d^{3} D_{\mathrm{j}}$, and the reactivity of these levels is investigated. The second excitation scheme is with the 


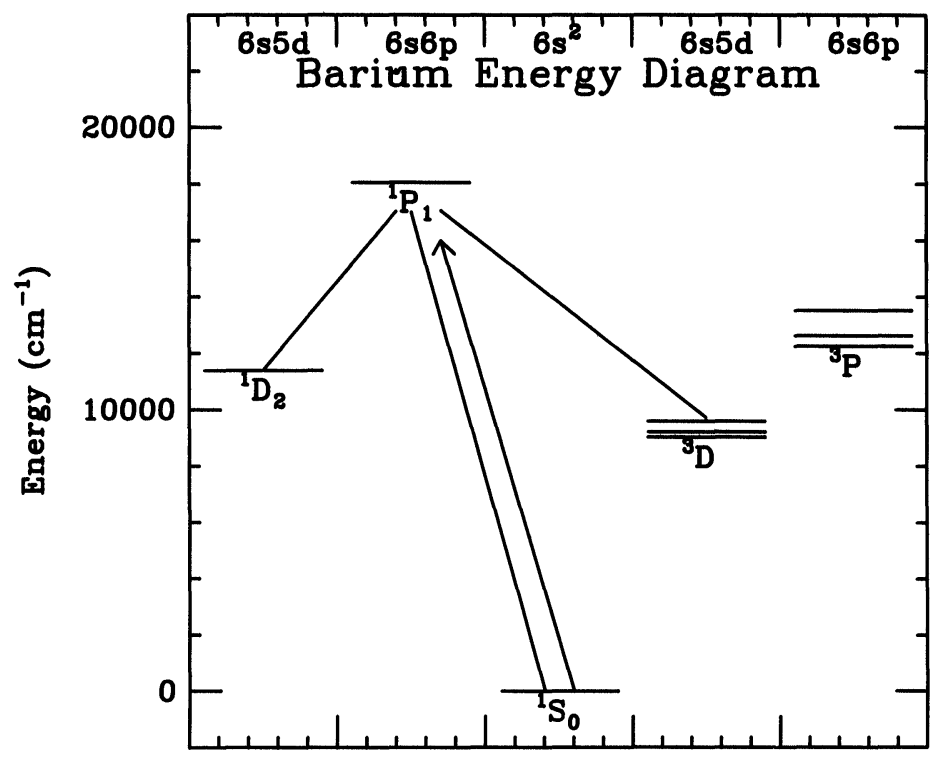

Figure 1 Energy diagram showing the lowest energy levels of barium. The solid line arrow corresponds to the laser excitation at $553 \mathrm{~nm}$. The other lines show the electronic transitions originating from $6 s 6 p^{1} P_{1}$ that allow optical pumping cycles.

laser beam sent into the crossing zone of the particle beams. The reactivity of $\mathrm{Ba}\left(6 s 6 p^{1} P_{1}, 6 s 5 d^{1} D_{2}, 6 s 5 d^{3} D\right)$ is then explored.

\section{REACTIONS OF ELECTRONICALLY EXCITED BARIUM ATOMS}

The reaction dynamics of metal atoms is expected to be different whether the metal atom is electronically excited or not. The large excitation energy associated to electronic transitions and the change in the nature of the potential surface initiating the reaction are both enough reason to justify this expectation. The reactivity of excited $\mathrm{Na}$ atoms has been reviewed recently, and we recall here some of the more important aspects. ${ }^{16}$ For instance in the case of $\mathrm{Na}$ reacting with $\mathrm{HCl}$, a substantial change in the reaction mechanisms has been observed when the sodium atom is excited from the ground electronic state $3 s$ to chosen excited states of higher and higher energy $3 p, 5 s$ and $4 d .{ }^{17}$ Moreover, the excited $\mathrm{Na}+\mathrm{O}_{2}$ reaction has shown a state selective behavior. The $\mathrm{Na}(4 d)$ atoms react with $\mathrm{O}_{2}$ whereas $\mathrm{Na}(5 s)$ atoms do not. ${ }^{18} \mathrm{~A}$ mechanism has been proposed for the $\mathrm{Na}(4 d)+\mathrm{O}_{2}$ reaction which involves a $\mathrm{Na}^{+}-\mathrm{O}_{2}-\left(A^{2} \Pi_{\mathrm{u}}\right)$ intermediate. ${ }^{19}$ Some aspects of the scattering of electronically excited Cs atoms are also discussed in Ref. 20.

The chemiluminescent reactions of electronically excited alkaline earth atoms renew the subject a great deal, as compared to reactions of excited alkali atoms. Two valence electrons then participate to the reaction. In the entrance channel this fact offers possibilities of excitation to atomic levels with a rich variety of electronic 
configurations. In the exit channels several products with various electronic configurations are often accessible energetically. Colliding electronically excited alkaline earth atoms with molecules thus allows to examine collision dynamics where many reactive and non reactive channels are coupled and compete one with each other.

Studying reactions of alkaline earth atoms has also an experimental advantage as compared to studying reactions of alkali atoms. Chemiluminescent reaction channels are opened that allow the internal state of the reaction product (both vibrational and electronic) to be checked directly through the analysis of chemiluminescence spectra. This has been widely used for reactions of ground state atoms ${ }^{1}$ and is used again here for reactions involving electronically excited barium atoms.

Among many interesting questions concerning the reactivity of excited barium atoms, the present article focusses on the following two:

1) What is the choice of the system when several chemiluminescence channels are opened?

2) Through which mechanism proceeds the reaction, when chemiluminescence is turned on by laser excitation.

III.1 What is the Choice of the System when Several Chemiluminescence Channels are Opened? Interpretation in Terms of Reaction Mechanism

This question was posed for the first time by Rettner and Zare in a situation where two different excited electronic states of the same reaction product were accessible (the states $A$ and $B$ of $\mathrm{CaCl}$ in the reaction $\left.\mathrm{Ca}\left({ }^{1} P_{1}\right)+\mathrm{HCl}\right) .{ }^{21}$ They showed that both states $A$ and $B$ are produced, but the branching ratio is affected by the alignment of the reacting ${ }^{1} P_{1}$ orbital.

The present article formulates the question differently. Situations are considered where several chemiluminescent reaction products are accessible energetically. Further questions then arise: are all the accessible reaction products formed, or is there selection amongst them? What is the electronic state of the products that are formed? In what follows, answers are given for excited $\mathrm{Ba}+\mathrm{H}_{2} \mathrm{O}, \mathrm{ROH}$ and $\mathrm{ROR}$ reactions ( $\mathrm{R}$ being an alkyl or allyl radical, and $\mathrm{Ba}$ excited to one of the levels $6 s 6 p^{1} P_{1}, 6 s 5 d^{1} D_{2}$ and $6 s 5 d^{3} D_{\mathrm{j}}$ ). These answers allow us to propose a mechanism that accounts for all these reactions.

\section{III.1.1 $\mathrm{Ba}\left(6 s 6 p^{1} P_{1}, 6 s 5 d^{1} D_{2}, 6 s 5 d^{3} D_{2}\right)+\mathrm{H}_{2} \mathrm{O}$}

The various chemiluminescent processes that are accessible energetically in $\mathrm{Ba}\left(6 s 6 p^{1} P^{1}, 6 s 5 d^{1} D_{2}, 6 s 5 d^{3} D\right)+\mathrm{H}_{2} \mathrm{O}$ collisions at $0.25 \mathrm{eV}$ are the following.

Reactions from the $6 s 6 p$ configuration of barium:

$$
\begin{aligned}
\mathrm{Ba}\left(6 s 6 p^{1} P_{1}\right)+\mathrm{H}_{2} \mathrm{O} & \longrightarrow \mathrm{BaO}\left(A^{1} \Sigma^{+}\right)+\mathrm{H}_{2} \quad \Delta \mathrm{H}=-0.89 \mathrm{eV} \\
& \longrightarrow \mathrm{BaO}\left(A^{\prime 1} \Pi\right)+\mathrm{H}_{2} \quad \Delta \mathrm{H}=-0.79 \mathrm{eV} \\
\mathrm{Ba}\left(6 s 6 p^{1} P_{1}\right)+\mathrm{H}_{2} \mathrm{O} & \longrightarrow \mathrm{BaOH}\left(A^{2} \Pi_{1} / 2\right)+\mathrm{H} \quad \Delta \mathrm{H}=-0.29 \mathrm{eV} \\
& \longrightarrow \mathrm{BaOH}\left(A^{2} \Pi_{3} / 2\right)+\mathrm{H} \quad \Delta \mathrm{H}=-0.21 \mathrm{eV} \\
& \longrightarrow \mathrm{BaOH}\left(B^{2} \Sigma^{+}\right)+\mathrm{H} \quad \Delta \mathrm{H}=-0.09 \mathrm{eV}
\end{aligned}
$$


Reactions from the $6 s 5 \mathrm{~d}$ configuration of barium:

$$
\begin{aligned}
& \mathrm{Ba}\left(6 s 5 d^{1} D_{2}\right)+\mathrm{H}_{2} \mathrm{O} \longrightarrow \mathrm{BaO}\left(A^{1} \Sigma^{+}\right)+\mathrm{H}_{2} \quad \Delta \mathrm{H}=-0.06 \mathrm{eV} \\
& \longrightarrow \mathrm{BaO}\left(A^{\prime 1} \Pi\right)+\mathrm{H}_{2} \quad \Delta \mathrm{H}=+0.04 \mathrm{eV} \\
& \mathrm{Ba}\left(6 s 5 d^{3} D_{2}\right)+\mathrm{H}_{2} \mathrm{O} \longrightarrow \mathrm{BaO}\left(A^{\prime} \Sigma^{+}\right)+\mathrm{H}_{2} \quad \Delta \mathrm{H}=+0.15 \mathrm{eV} \\
& \longrightarrow \mathrm{BaO}\left(A^{\prime 1} \Pi\right)+\mathrm{H}_{2} \quad \Delta \mathrm{H}=+0.25 \mathrm{eV}
\end{aligned}
$$

The bonding energies retained for calculating the energetics of processes (1-4) are the following: $\mathrm{Ba}-\mathrm{O} 5.75 \mathrm{eV},{ }^{1} \mathrm{O}-\mathrm{H}_{2} 5.027 \mathrm{eV}$ and $\mathrm{H}-\mathrm{OH} 5.114 \mathrm{eV}^{22}$ and $\mathrm{Ba}-\mathrm{OH} 4.6 \mathrm{eV} .^{23}$

The luminescence spectrum shown in Figure 2 was obtained with the excitation scheme of barium where the laser beam is sent inside the reaction zone directly. Results of Figure 2 thus correspond to collisions of barium atoms excited to the $6 s 6 p^{1} P_{1}, 6 s 5 d^{1} D_{2}$ and $6 s 5 d^{3} D_{\mathrm{j}}$ levels. The collision energy is $0.25 \mathrm{eV}$. Assignments of the features observed in this spectrum has been discussed extensively in Ref. 6 The intense feature at $791 \mathrm{~nm}$ is the intercombination line $\mathrm{Ba}\left(6 s 6 p^{3} P_{1} \rightarrow 6 s^{2}{ }^{1} S_{0}\right)$. The ${ }^{3} P_{1}$ state of barium was populated by the following two collision processes:

$$
\begin{aligned}
& \mathrm{Ba}\left(6 s 6 p^{1} P_{1}\right)+\mathrm{H}_{2} \mathrm{O} \longrightarrow \mathrm{Ba}\left(6 s 6 p^{3} P_{1}\right)+\mathrm{H}_{2} \mathrm{O} \Delta \mathrm{H}=-0.67 \mathrm{eV} \\
& \mathrm{Ba}\left(6 s 5 d^{1} D_{2}\right)+\mathrm{H}_{2} \mathrm{O} \longrightarrow \mathrm{Ba}\left(6 s 6 p^{3} P_{1}\right)+\mathrm{H}_{2} \mathrm{O} \Delta \mathrm{H}=+0.15 \mathrm{eV}
\end{aligned}
$$

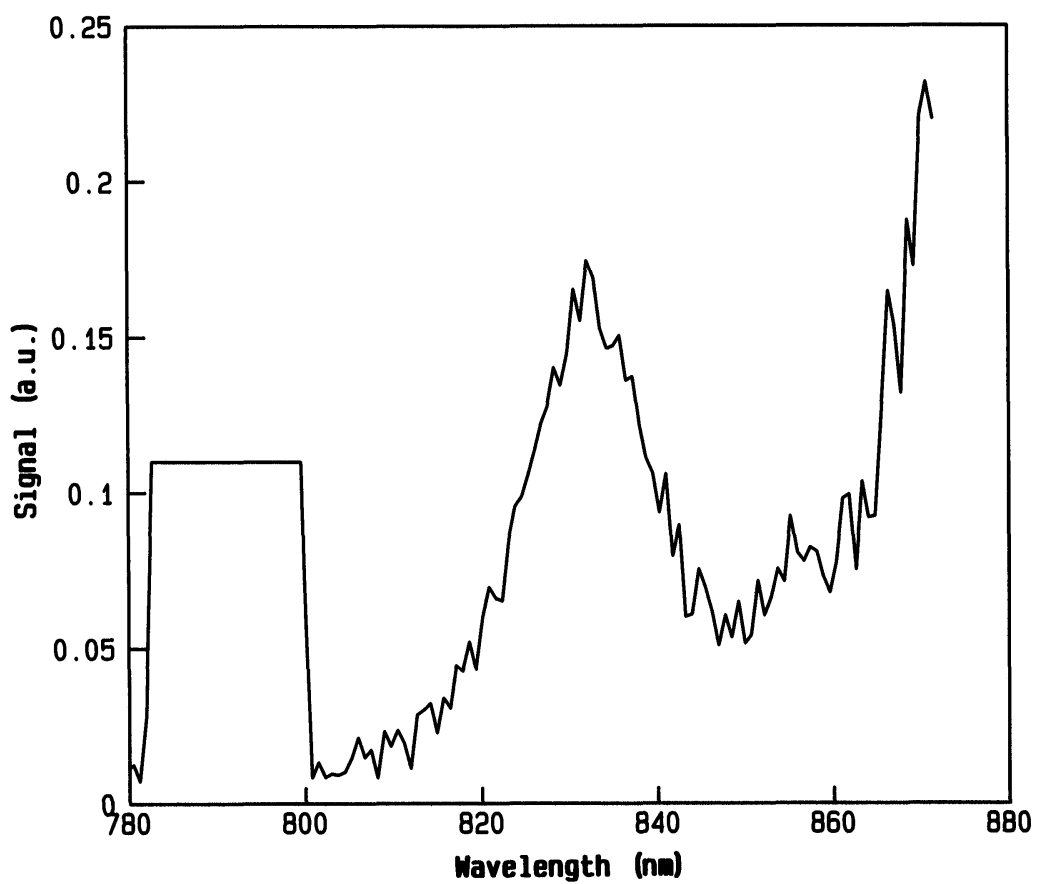

Figure 2 Luminescence spectrum observed in reactions of $\mathrm{Ba}\left(6 s 6 p^{1} P_{1}, 6 s 5 d^{1} D_{2}\right.$ and $\left.6 s 5 d^{3} D_{\mathrm{j}}\right)$ with $\mathrm{H}_{2} \mathrm{O}$ at $0.25 \mathrm{eV}$ collision energy. The spectrum was recorded with a resolution of $12 \mathrm{~nm}$ and is corrected for the transmission of the detection system. The intense emission at $791 \mathrm{~nm}$ originates from the $6 s 6 p^{3} P_{1}$ level of $\mathrm{Ba}$. It is truncated for clarity. 
The other features at 755, 832 and $875 \mathrm{~nm}$ in Figure 2 are assigned to chemiluminescence of $\mathrm{BaOH}$ through the transitions $B^{2} \Sigma^{+} \rightarrow X^{2} \Sigma^{+}, A^{2} \Pi_{3 / 2} \rightarrow X^{2} \Sigma^{+}$and $A^{2} \Pi_{1 / 2} \rightarrow X^{2} \Sigma^{+}$respectively. No feature in Figure 2 can be assigned to $\mathrm{BaO}$ chemiluminescence. As a consequence, among the processes 1-4 given above, only $2 \mathrm{a}, 2 \mathrm{~b}$ and $2 \mathrm{c}$ contribute to the chemiluminescence.

These results are complemented by other information based on laser induced fluorescence detection. We have shown that the ground state $\mathrm{BaOH}$ is formed from $\mathrm{Ba}\left(6 s 5 d^{1} D_{2}, 6 s 5 d^{3} D_{\mathrm{j}}\right)+\mathrm{H}_{2} \mathrm{O}$ collisions. A full account of this work will be published later. Related experiments have been performed at Berkeley using a crossed molecular beam machine and detecting the angular and velocity distribution of both ground state and excited state reaction products. $\mathrm{Ba}\left(6 s 5 d^{1} D_{2}, 6 s 5 d^{3} D\right)$ has been made react to $\mathrm{H}_{2} \mathrm{O}$ at various collision energies. Among the two energetically allowed products $\mathrm{BaO}$ and $\mathrm{BaOH}$, only $\mathrm{BaOH}$ has been detected. ${ }^{24}$

The observations made so far on excited $\mathrm{Ba}+\mathrm{H}_{2} \mathrm{O}$ reactions can be summarized as follows:

i) The excited levels $6 s 5 d^{1} D_{2}$ and $6 s 5 d^{3} D_{\mathrm{j}}$ of $\mathrm{Ba}$ do not lead to observable chemiluminescence although chemiluminescence channels forming $\mathrm{BaO}$ are allowed energetically.

ii) The only reactive channel for the excited levels $6 s 5 d^{1} D_{2}$ and $6 s 5 d^{3} D_{\mathrm{j}}$ of $\mathrm{Ba}$ is the formation of ground state $\mathrm{BaOH}$. Formation of ground state $\mathrm{BaO}$ is not observed.

iii) The level $6 s 6 p^{1} P_{1}$ is the lowest excited state of $\mathrm{Ba}$ which leads to chemiluminescence. The chemiluminescence originates from $\mathrm{BaOH}\left(A^{2} \Pi_{1 / 2}, A^{2} \Pi_{3 / 2}\right.$, $B^{2} \Sigma_{1 / 2}$ ) only, and not from the energetically favored channel forming excited $\mathrm{BaO}$.

\section{III.1.2 $B a\left(6 s 6 p^{1} P_{1}, 6 s 5 d^{1} D_{2}, 6 s 5 d^{3} D_{j}\right)+$ alcohols}

Chemiluminescence of $\mathrm{BaO}, \mathrm{BaOH}$ and $\mathrm{BaOR}$ is allowed energetically from reactions of excited barium with alcohols $\mathrm{R}-\mathrm{O}-\mathrm{H}$ ( $\mathrm{R}$ being an alkyl or the allyl radical). Let us now see which product is formed.

Figure 3 shows the luminescence spectra resulting from reactions of methanol and water with excited barium atoms. The barium atoms are excited with the pump laser beam sent into the reaction zone. Results of Figure 3 thus correspond to reactions of $\mathrm{Ba}\left(6 s 6 p^{1} P_{1}, 6 s 5 d^{1} D_{2}, 6 s 5 d^{3} D_{\mathrm{j}}\right)$. The collision energy is $0.25 \mathrm{eV}$. The dashed curve corresponds to the reactant $\mathrm{CH}_{3} \mathrm{OH}$, and the full curve to $\mathrm{H}_{2} \mathrm{O}$. The curve for $\mathrm{H}_{2} \mathrm{O}$ is drawn for comparison purposes. It duplicates that shown in Figure 2.

The two spectra observed in Figure 3 are qualitatively similar. In particular the intense feature at $791 \mathrm{~nm}$ exists for both reactant indicating that both methanol and water are able to induce singlet-triplet transfers in $\mathrm{Ba}$. Of more interest is the small but significant differences that exist between the two spectra:

i) The feature at $755 \mathrm{~nm}$ exists for $\mathrm{H}_{2} \mathrm{O}$ only,

ii) The feature at $832 \mathrm{~nm}$ for $\mathrm{H}_{2} \mathrm{O}$ is blue shifted to $826 \mathrm{~nm}$ for $\mathrm{CH}_{3} \mathrm{OH}$, and its width is smaller for $\mathrm{CH}_{3} \mathrm{OH}$ than for $\mathrm{H}_{2} \mathrm{O}$. 


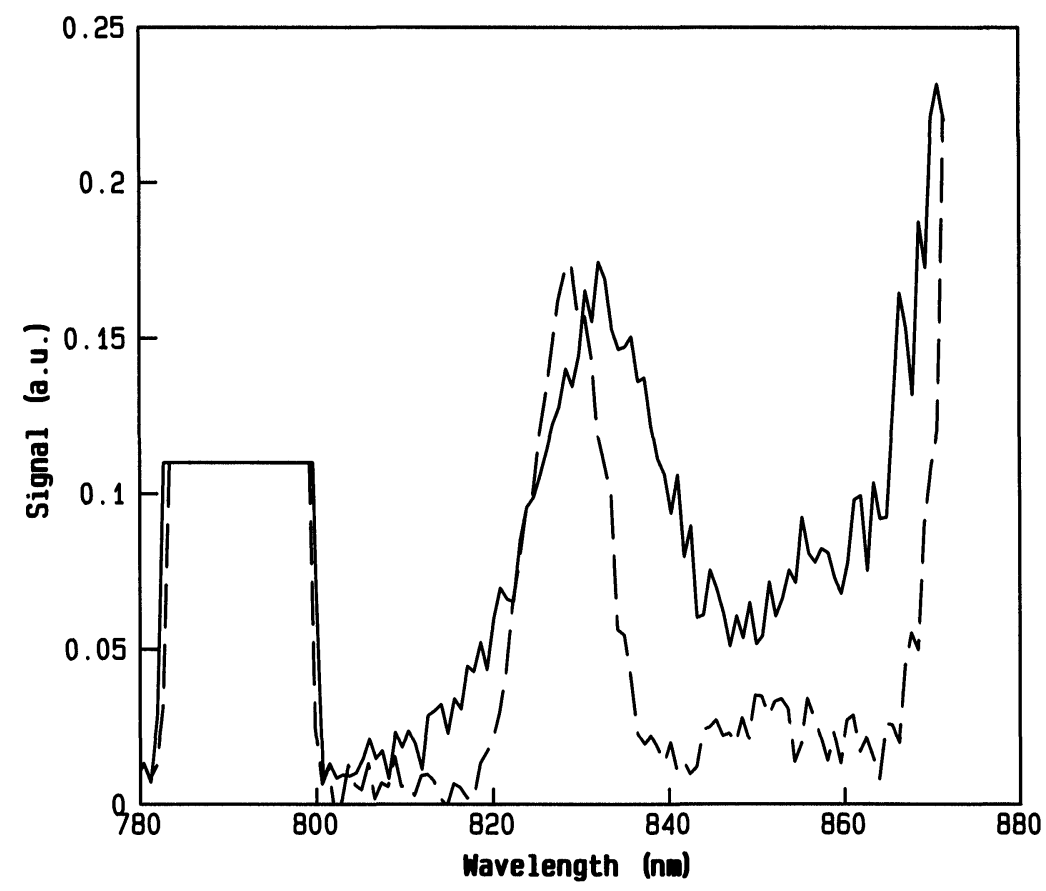

Figure 3 Luminescence spectrum observed in reactions of $\mathrm{Ba}\left(6 s 6 p^{1} P_{1}, 6 s 5 d^{1} D_{2}\right.$ and $\left.6 s 5 d^{3} D_{\mathrm{j}}\right)$ with $\mathrm{H}_{2} \mathrm{O}$ (solid line) and $\mathrm{CH}_{3} \mathrm{OH}$ (dashed line) at $0.25 \mathrm{eV}$ collision energy. Otherwise, same caption as Figure 2 .

iii) The blue part of the feature at $875 \mathrm{~nm}$ shown in Figure 3 suggests also a difference in width and/or position between the two spectra.

These differences are at the limit of the $12 \mathrm{~nm}$ spectral resolution of the experiment shown in Figure 3. They were confirmed by a $0.2 \mathrm{~nm}$ resolution experiment that was performed under a beam-jet configuration of the machine. ${ }^{25}$ From the high resolution experiment, it can be concluded that the chemiluminescent emission with $\mathrm{CH}_{3} \mathrm{OH}$ peaks at $825.9 \mathrm{~nm}$. It is assigned to the $A-X$ transition of the methoxide $\mathrm{BaOCH}_{3}{ }^{26}$

Other experiments were run for a number of alcohols ROH (ethanol, propanol-1, propanol-2, methyl-2 propanol-2, $n$-butanol, and allyl-alcohol). In each case, the chemiluminescent product was assigned to the alkoxide $\mathrm{BaOR}$ rather than to $\mathrm{BaOH}$ or $\mathrm{BaO}$.

\section{III.1.3 Mechanism for excited $\mathrm{Ba}+\mathrm{H}_{2} \mathrm{O}, \mathrm{ROH}$ reactions}

A reaction mechanism is discussed that accounts for the above observations.

Formation of $\mathrm{BaO}$ has not been observed in reactions of excited barium with neither water nor alcohols. This is most likely due to the fact that formation of $\mathrm{BaO}$ would involve a substantial bond rearrangement. For instance, with water, 
formation of $\mathrm{BaO}$ supposes that the two $\mathrm{OH}$ bonds are broken and that two other bonds $\mathrm{Ba}-\mathrm{OH}$ and $\mathrm{H}-\mathrm{H}$ are formed. This is expected to induce barriers on the potential surface that hinder a reaction path leading to $\mathrm{BaO}$ formation. The reaction of excited barium either with water or alcohol thus follows another path.

A likely mechanism has been proposed in Ref. 6 for reaction with water. The reaction is initiated by an adduct:<smiles>[18CH2]CO</smiles>

The adduct converts by $\mathrm{H}$ migration into the insertion product $\mathrm{H}-\mathrm{Ba}-\mathrm{OH}$. Since $\mathrm{H}-\mathrm{Ba}-\mathrm{OH}$ has a large excess energy it fragments into $\mathrm{BaOH}+\mathrm{H}$ by rupture of the $\mathrm{Ba}-\mathrm{H}$ bond. Let us mention that formation of $\mathrm{BaH}+\mathrm{OH}$ by the other fragmentation path of $\mathrm{H}-\mathrm{Ba}-\mathrm{OH}$ is not allowed energetically, and thus cannot be observed.

This mechanism is easy to extend to alcohols. The collision of excited Ba with an alcohol $\mathrm{ROH}$ creates an adduct similar to (7):<smiles>[R]O[10BH2]</smiles>

The essential difference between the adducts (7) and (8) is that (8) is not symmetri$\mathrm{cal}$, and that two different migrations may be imagined. That of $\mathrm{H}$, forming the insertion product $\mathrm{H}-\mathrm{Ba}-\mathrm{OR}$, and that of $\mathrm{R}$ forming $\mathrm{HO}-\mathrm{Ba}-\mathrm{R}$. The experimental observation shows that the alkoxide is formed preferentially. This implies that the insertion product $\mathrm{H}-\mathrm{Ba}-\mathrm{OR}$ predominates over $\mathrm{HO}-\mathrm{Ba}-\mathrm{R}$. Our results thus show that migration of $\mathrm{H}$ predominates over that of $\mathrm{R}$. In other words, excited barium atoms react with alcohols $\mathrm{R}-\mathrm{O}-\mathrm{H}$ through an insertion mechanism, and are more likely to insert into the $\mathrm{O}-\mathrm{H}$ bond rather than into the $\mathrm{R}-\mathrm{O}$ bond.

The difficulty of barium to insert into an $\mathrm{O}-\mathrm{R}$ bond to form chemiluminescent products has been checked directly by reacting barium with dimethyl, diethyl and diallyl ethers $\left(\mathrm{R}-\mathrm{O}-\mathrm{R}\right.$ with $\mathrm{R}=\mathrm{CH}_{3}, \mathrm{C}_{2} \mathrm{H}_{5}$ and $\mathrm{CH}_{2}=\mathrm{CH}-\mathrm{CH}_{2}$ respectively). In all cases, although formation of chemiluminescent products $\mathrm{BaOR}$ is allowed energetically, no chemiluminescence assignable to ether reactions were observed.

Interestingly, the present reaction mechanism that is proposed for chemiluminescent reaction channels of $\mathrm{Ba}\left(6 s 6 p^{1} P_{1}, 6 s 5 d^{1} D_{2}\right.$ and $\left.6 s 5 d^{3} D\right)$ also applies for non chemiluminescent channels in $\mathrm{Ba}\left(6 s 5 d^{1} D_{2}, 6 s 5 d^{3} D\right)$ reactions. Exclusive or quasiexclusive formation of $\mathrm{BaOCH}_{3}$ is seen indeed in $\mathrm{Ba}\left(6 s 5 d^{1} D_{2} 6 s 5 d^{3} D\right)$ reactions with $\mathrm{CH}_{3} \mathrm{OD}$, whereas no reaction product was seen in reactions with dimethyl ether. ${ }^{24}$ These observations are in accordance with the expectations of the above model.

III.2 Through Which Mechanism Proceeds the Reaction, when Chemiluminescence is Turned on by Laser Excitation

Reaction of ground state barium with $\mathrm{O}_{2}$ is a typical example where the reaction goes through the formation of a long lived intermediate, although the $\mathrm{Ba} / \mathrm{O}_{2}$ systems has 
few degrees of freedom. ${ }^{27-29}$ The existence of the intermediate is interpreted by the occurrence of a deep well along the reaction path. ${ }^{29}$

The present review aims to discuss whether this mechanism adequately describes chemiluminescence from $\mathrm{Ba}\left(6 s 6 p^{1} P_{1}, 6 s 5 d^{1} D_{2}\right.$ and $\left.6 s 5 d^{3} D\right)+\mathrm{O}_{2}$ reactions.

\section{III.2.1 $\mathrm{Ba}\left(6 s 5 d^{1} \mathrm{D}_{2}, 6 s 5 d^{3} \mathrm{D}\right)+\mathrm{O}_{2}$}

Table 1 shows that even for the low excited configuration $6 s 5 d$ of $\mathrm{Ba}$, many luminescent channels are opened above $0.13 \mathrm{eV}$ collision energy.

Table 1 Exoergicity (in $\mathrm{eV}$ ) of the reactions:

$$
\begin{aligned}
& \mathrm{Ba}(6 s n \mathrm{~L})+\mathrm{O}_{2}\left(\mathrm{X}^{3} \Sigma \longrightarrow \mathrm{BaO}\left(\mathrm{A}, \mathrm{a}, \mathrm{A}^{\prime} \text { and } \mathrm{b}\right)+\mathrm{O}\left({ }^{3} P\right)\right. \\
& \mathrm{Ba}(6 s n \mathrm{~L})+\mathrm{O}_{2}\left(\mathrm{X}^{3} \Sigma \longrightarrow \mathrm{Ba}\left(6 s 6 p^{3} P_{1}\right)+\mathrm{O}_{2}\left(\mathrm{X}^{3} \Sigma\right)\right.
\end{aligned}
$$

\begin{tabular}{lccccc}
\hline $\begin{array}{l}\text { Entrance channel } \\
\mathrm{Ba}+\mathrm{O}_{2}(\mathrm{X}) \\
\text { States of } \mathrm{Ba}\end{array}$ & \multicolumn{7}{c}{$\begin{array}{l}\text { Exit channel } \\
\mathrm{BaO}+\mathrm{O}\left({ }^{3} \mathrm{P}\right) \\
\text { States of } \mathrm{BaO}\end{array}$} \\
\hline & $A^{1} \Sigma^{+}$ & \multicolumn{2}{c}{$a^{3} \Sigma^{+}$} & $A^{\prime 1} \Pi$ & \multicolumn{1}{c}{$\begin{array}{l}\text { Exit channel } \\
\mathrm{Ba}\left({ }^{3} P_{1}\right)+\mathrm{O}_{2}\end{array}$} \\
\hline $6 s 6 p^{1} P_{1}$ & 0.80 & 0.82 & 0.70 & 0.71 & 0.067 \\
$6 s 5 d^{1} D_{2}$ & -0.03 & -0.002 & -0.13 & -0.11 & -0.15 \\
$6 s 5 d^{3} D_{2}$ & -0.30 & -0.27 & -0.40 & -0.38 & -0.37 \\
\hline
\end{tabular}

There has been some ambiguity whether all these channels participate to the chemiluminescence. It was thought indeed that chemiluminescence from $\mathrm{BaO}$ should originate from the excited singlet terms $A^{1} \Sigma^{+}$and $A^{\prime} \Pi$ only. Our recent work ${ }^{7}$ has brought the evidence that triplet states also participate to the chemiluminescence. Therefore, all the processes listed in Table 1 which are accessible energetically must be considered in order to account for the observed chemiluminescence spectra.

Chemiluminescence resulting in $\mathrm{Ba}\left(6 s 5 d^{1} D_{2}, 6 s 5 d^{3} D\right)$ collisions with $\mathrm{O}_{2}$ has been measured at $0.11,0.20,0.24,0.32,0.58,0.74$ and $0.93 \mathrm{eV}$ collision energy. Some chemiluminescence spectra are shown in Figure 4.

The observations can be summarized as follow:

i) Above $0.15 \mathrm{eV}$ collision energy, collisional population of $\mathrm{Ba}\left(6 s 6 p^{3} P_{1}\right)$ is accessible energetically, and the intercombination line $6 s 6 p^{3} P_{1} \rightarrow 6 s^{2}{ }^{1} S_{0}$ is observed in the spectra.

ii) The remainder of the spectra is due to the chemiluminescent emission of $\mathrm{BaO}$. A vibrational structure is clearly visible at collision energies between 0.11 and $0.32 \mathrm{eV}$. It is washed out at the three highest collision energies explored.

\section{III.2.2 $\mathrm{Ba}\left(6 s 6 p^{1} P_{1}\right)+\mathrm{O}_{2}$}

The series of experiments reported here for excited $\mathrm{Ba}+\mathrm{O}_{2}$ reactions was with the laser beam sent into the reaction zone. Chemiluminescence then results from reaction of the three levels $6 s 6 p^{1} P_{1}, 6 s 5 d^{1} D_{2}$ and $6 s 5 d^{3} D$ of barium. Combining these 


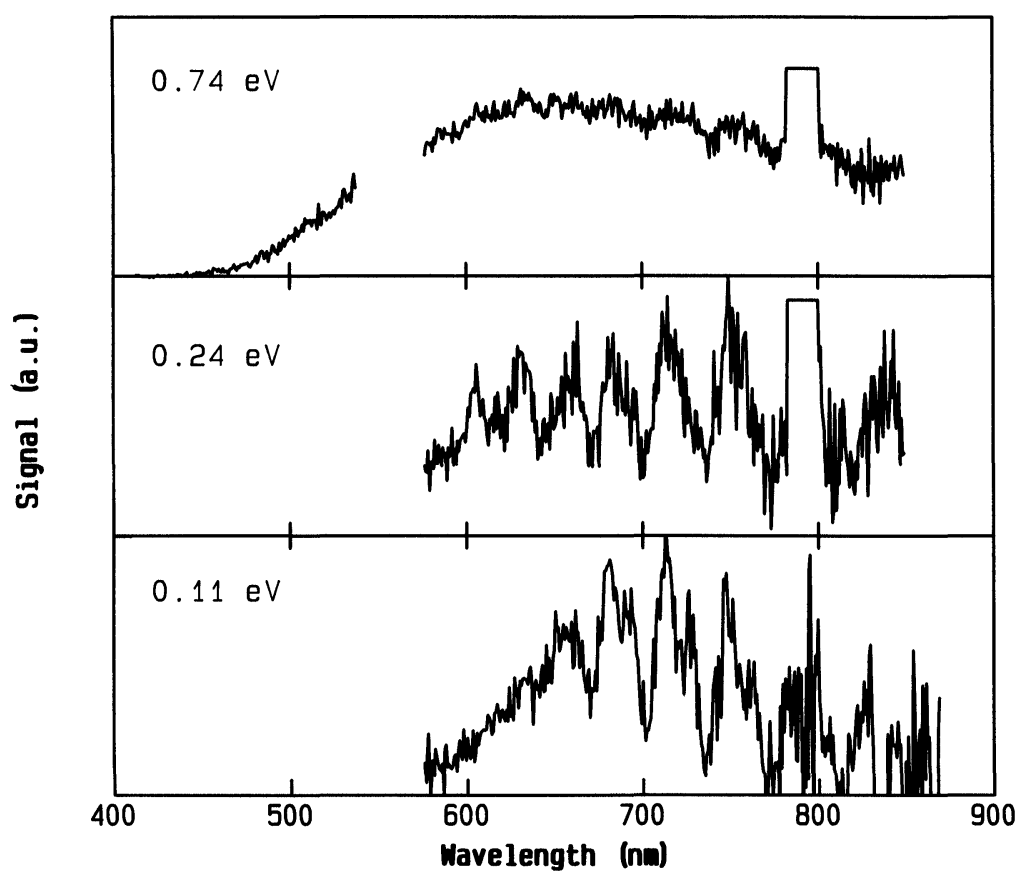

Figure 4 Luminescence spectrum observed in reactions of $\mathrm{Ba}\left(6 s 5 d^{1} D_{2}\right.$ and $\left.6 s 5 d^{3} D_{\mathrm{j}}\right)$ with $\mathrm{O}_{2}$ at $0.11,0.24$ and $0.74 \mathrm{eV}$ collision energy. The spectrum at $0.74 \mathrm{eV}$ is not shown between 525 and $575 \mathrm{~nm}$ since it is overwhelmed by the intense resonance line $6 s 6 p^{1} P_{1} \rightarrow 6 s^{2}{ }^{1} S_{0}$ of barium at $553 \mathrm{~nm}$. Otherwise, same caption as Figure 2.

experiments with those reported above it is possible to extract the contribution of $6 s 5 d^{1} D_{2}$ and $6 s 5 d^{3} D$ and get information on chemiluminescence from reactions of pure $6 s 6 p^{1} P_{1}$ barium atoms. Some results directly relevant to the reaction mechanism are reported here. A full account of the work will be reported later.

The experiments were performed between 0.1 and $1 \mathrm{eV}$. One chemiluminescence spectrum is shown in Figure 5 for the $0.11 \mathrm{eV}$ collision energy. The spectrum is much less structured than the one shown in Figure 4 at the same collision energy with $\mathrm{Ba}\left(6 s 5 d^{1} D_{2}\right)$ reacting. This results from the $0.83 \mathrm{eV}$ increase of available energy when switching from $6 s 5 d^{1} D_{2}$ to $6 s 6 p^{1} P_{1}$.

\section{III.2.3 Mechanism for excited $\mathrm{Ba}+\mathrm{O}_{2}$ chemiluminescent reactions}

The spectra of Figure 4 and 5 together with those obtained at the other collision energies explored contain the desired information about the reaction mechanism and about its evolution with the collision energy. We have shown in Ref. 5 for $\mathrm{Ba}\left(6 s 6 p^{1} P_{1}\right)+\mathrm{CO}_{2}$, and in Ref. 7 for $\mathrm{Ba}\left(6 s 5 d^{1} D_{2}, 6 s 5 d^{3} D_{\mathrm{j}}\right)+\mathrm{O}_{2}$ how to extract this information: (i) the observed spectra are simulated using assumed distributions of rovibrational and electronic state populations, and (ii) these populations are compared to the predictions of statistical models. 


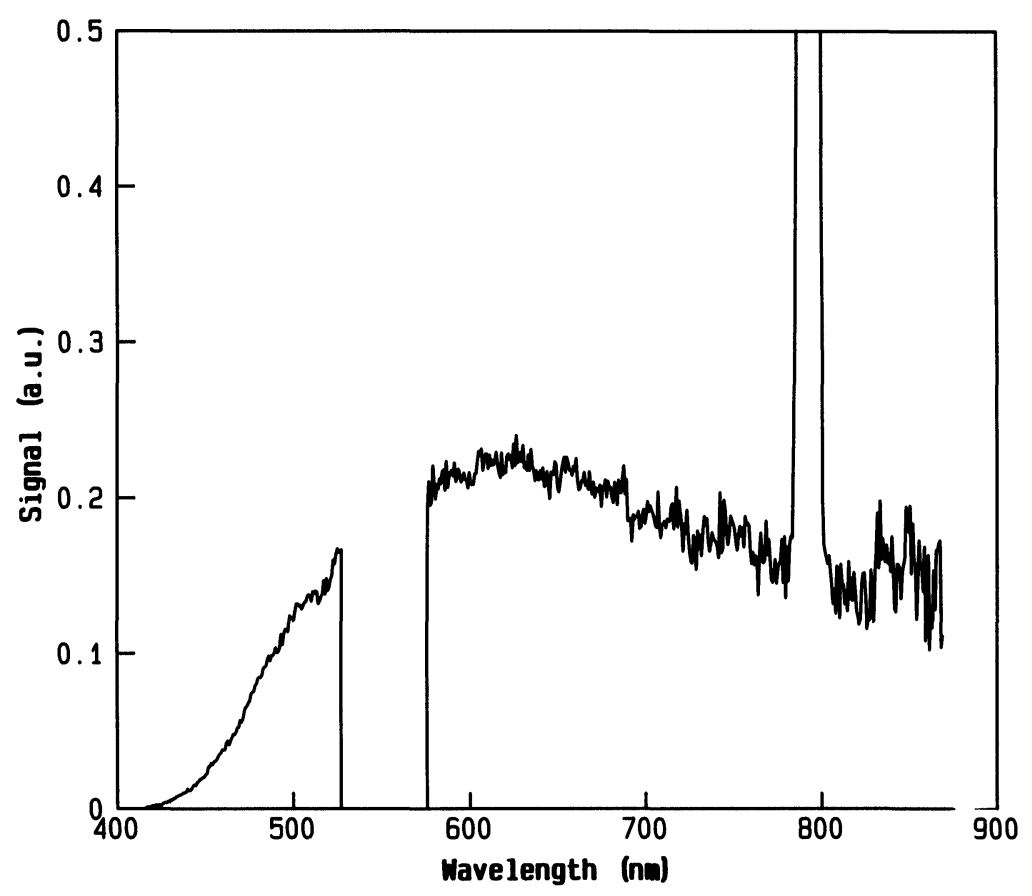

Figure 5 Luminescence spectrum observed in reaction of $\mathrm{Ba}\left(6 s 6 p^{1} P_{1}\right)$ with $\mathrm{O}_{2}$ at $0.10 \mathrm{eV}$ collision energy. The spectrum is not shown between 525 and $575 \mathrm{~nm}$ since it is overwhelmed by the intense resonance line $6 s 6 p^{1} P_{1} \rightarrow 6 s^{2}{ }^{1} S_{0}$ of barium at $553 \mathrm{~nm}$. Otherwise, same caption as Figure 2.

The phase space model is relevant for discussing the excited $\mathrm{Ba}+\mathrm{O}_{2}$ reactions. The details about phase space calculations are given in Ref. 7. However, it is important to recall that the model assumes the formation of a long lived collision complex, and that it assumes dissociation of the complex with equal probabilities among all the accessible quantum states of the system. The dynamical constraints of the model are minimum. They include conservation of energy and total angular momentum. No potential barrier, except centrifugal barrier, is assumed by the model to prevent the formation and the dissociation of the collision complex.

The first important result is that phase space calculations for $\mathrm{Ba}\left(6 s 5 d^{1} D_{2}\right)+\mathrm{O}_{2}$ collisions up to $0.58 \mathrm{eV}$ reproduce the electronic and rovibrational state distributions that fit the observed chemiluminescence spectra. ${ }^{7}$ A side result may suggest that predictions of the phase space model depart from the experimental observations above $0.6 \mathrm{eV}$ collision energy.

The second important result is that phase space calculations never reproduce the experimental spectra for $\mathrm{Ba}\left(6 s 6 p^{1} P_{1}\right)+\mathrm{O}_{2}$ collisions.

At this point, we are left with the conclusion that reaction of $\mathrm{Ba}\left(6 s 5 d^{1} \mathrm{D}_{2}\right)$ with $\mathrm{O}_{2}$ leads to excited $\mathrm{BaO}$ molecules with a phase space distribution of internal and electronic states for collision energies up to $0.6 \mathrm{eV}$. This strongly suggests that the reaction goes through a long lived complex as assumed by the phase space model. In 
contrast, the mechanism is different for chemiluminescent reactions of $\mathrm{Ba}\left(6 s 6 p^{1} P_{1}\right)$ with $\mathrm{O}_{2}$. Two reasons may be invoked. Either the $\mathrm{Ba}\left(6 s 6 p^{1} P_{1}\right) / \mathrm{O}_{2}$ system never really goes through a long lived complex, or the branching to chemiluminescence in the exit channel involved couplings that put a bias on the statistical energy distribution.

\section{REACTIONS OF GROUND STATE AND ELECTRONICALLY EXCITED BARIUM ATOMS WITH MOLECULAR CLUSTERS}

Large van der Waals clusters have attracted a growing interest over the past few years. A recent Faraday Symposium devoted to "Large Gas Phase Clusters" has shown the current interest in this field. ${ }^{30}$ Most papers were concerned with (i) the fragmentation processes and intracluster reactions that follow ionization or electron attachment, (ii) structural properties and spectroscopy, and (iii) phase transitions. All these topics concern "internal" properties of the van der Waals clusters.

Very little work has been performed on reactions of large van der Waals clusters with atoms and molecules. This is very surprising considering the large interest of such processes. They indeed yield information about chemical reactions in "solvated media". Pioneering work in the field was done on large $\mathrm{CH}_{3} \mathrm{I}$ clusters reacting with $\mathrm{Rb}^{8}$ The reaction product was identified as a heavy product, possibly a solvated $\mathrm{RbI}$ molecule or a long-lived $\mathrm{Rb}\left(\mathrm{CH}_{3} \mathrm{I}\right) n$ complex. More recently, reaction between barium atoms and van der Waals clusters have been investigated, but that concerned van der Waals dimers of $\mathrm{NO}_{2}, \mathrm{SO}_{2}$ and $\mathrm{CO}_{2} \cdot{ }^{9-11} \mathrm{~A}$ short reference is done to reaction of $\mathrm{Ba}$ with large $\mathrm{CO}_{2}$ clusters in ${ }^{10}$ which also suggests the existence of heavy solvated reaction products.

Reactions of ground state and electronically excited barium atoms with large van der Waals clusters have been investigated in this laboratory. ${ }^{12}$

The clusters were generated by the intense cooling due to the supersonic expansion of the molecular beam source. Low temperature, and large pressure in the stagnation chamber generating the beam stimulates cluster formation. It was found that the yield of cluster formation is tremendously larger when expanding a mixture of argon with the molecular gas that is to be clusterized. Argon is playing the role of an efficient cooling agent. In particular, by optimizing the expansion conditions of $\mathrm{H}_{2} \mathrm{O}$ /Ar mixtures, it was possible to create beams containing argon and large $\mathrm{H}_{2} \mathrm{O}$ clusters, with no water monomer present in the beam. With the beam operating under such a "large cluster only" regime, one can estimate the size of the large clusters as 10 monomers or more.

Control of cluster abundance in the beam is an important question for these experiments. It is based on time-of-flight measurements of velocity distributions in the beam. The method is thoroughly explained in Ref. 31. Let us just recall that it allows us to determine the flux of free monomers remaining in the beam after the supersonic expansion.

We have shown that the reaction of ground state barium with large $\mathrm{N}_{2} \mathrm{O}$ clusters has a much weaker chemiluminescence yield than reaction with $\mathrm{N}_{2} \mathrm{O}$ monomers. A 
similar observation was done with $\mathrm{Ba}\left(6 s 6 p^{1} P_{1}\right)$ colliding large $\mathrm{CO}_{2}$ and $\mathrm{H}_{2} \mathrm{O}$ clusters, since no chemiluminescence was detected in these experiments. Interestingly, collisions with large $\mathrm{CO}_{2}$ and $\mathrm{H}_{2} \mathrm{O}$ clusters do not induce the transition $6 s 6 p^{1} P_{1} \rightarrow$ $6 s 6 p^{3} P_{1}$ that is observed with $\mathrm{CO}_{2}$ and $\mathrm{H}_{2} \mathrm{O}$ monomers.

The results with $\mathrm{N}_{2} \mathrm{O}$ have been interpreted in Ref. 12 on the ground of electron attachment properties of $\mathrm{N}_{2} \mathrm{O}$ clusters. ${ }^{32}$ Figure 6 pictures that (i) dissociative electron attachment to $\mathrm{N}_{2} \mathrm{O}$ clusters is possible with low energy electrons, and (ii) formation of solvated $\mathrm{O}^{-}$ions is energetically the most favorable exit channel in dissociative electron attachment to $\mathrm{N}_{2} \mathrm{O}$ clusters. These two properties then allow us to propose that barium atoms colliding $\mathrm{N}_{2} \mathrm{O}$ clusters, enter into the cluster, and induces a dissociative attachment by transfer of one of its valence electrons to the cluster. Considering the large solvation energy of both $\mathrm{Ba}^{+}$and $\mathrm{O}^{-}$ions, we
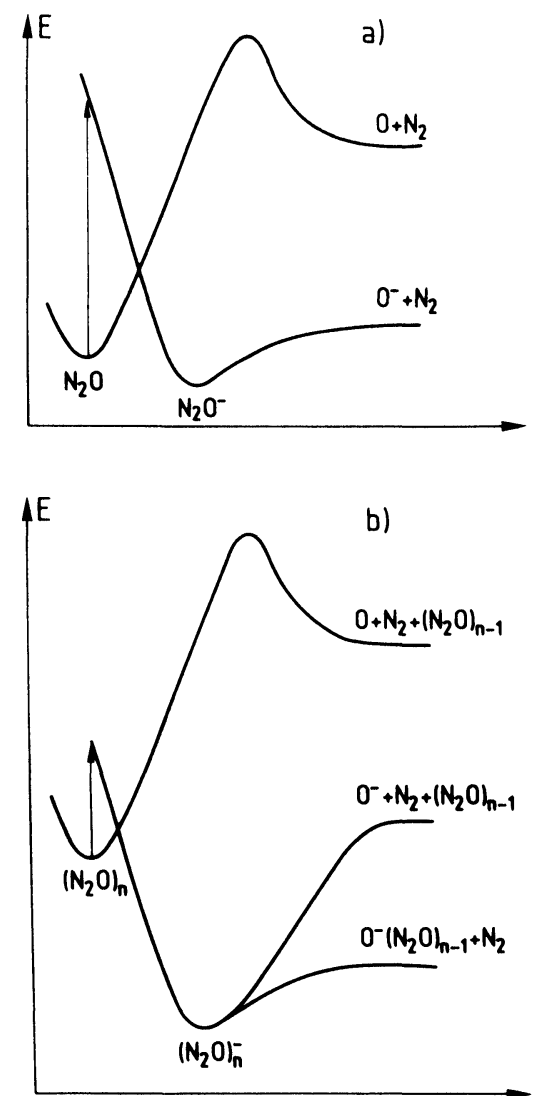

Figure 6 Shape of the potentials of $\mathrm{N}_{2} \mathrm{O}$ monomer (part a) and cluster (part b) along a hypothetical $\mathrm{N}_{2}-\mathrm{O}$ coordinate. The polymer curves are derived from the monomer by accounting for solvation energies. Curves where neutral are solvated are shifted by an amount equal to van der Waals interactions (a few tenths of an $\mathrm{eV}$ ) whereas curves where $\mathrm{O}^{-}$is solvated are shifted by its solvation energy (more than one $\mathrm{eV}$ ). The arrows show the vertical electroaffinities. (from ${ }^{12}$. Reproduced with the permission of the American Institute of Physics). 
propose that reaction of barium with $\mathrm{N}_{2} \mathrm{O}$ clusters results in formation of a heavy product which probably is also $\mathrm{BaO}$ solvated by $\mathrm{N}_{2} \mathrm{O}$ molecules. The experiment shows that this product is not formed in a chemiluminescent state that emits inside the spectral range $400-900 \mathrm{~nm}$ where chemiluminescence from monomers is observed.

Interpretation of the collisions between barium atoms and clusters of $\mathrm{CO}_{2}$ and $\mathrm{H}_{2} \mathrm{O}$ goes along the same model. We are thus left with the conclusion that formation of heavy solvated products in these collisions is a fairly general situation. These observations and the interpretation model proposed here are entirely consistent with the results of Refs. 8,10 that are recalled above. Further work is in progress in this laboratory to analyse in more detail the formation mechanism of the heavy solvated compounds.

\section{CONCLUSIONS}

We provided a description of the various types of experiments that can be performed with the crossed molecular beam machine of this laboratory. The reactivity of excited barium atoms with a number of molecules and molecular clusters were reviewed, but no extensive presentation of the results was given since they are the subject of other publications.

The first subject presented here showed that reactions of excited barium atoms with water and alcohols are accounted by the same reaction mechanism where barium inserts into an $\mathrm{OH}$ bond. This mechanism accounts for the absence of (or very small) reactivity of excited $\mathrm{Ba}$ with ethers.

The second subject presented showed to which extent adding electronic energy to a reactive system changes the reaction mechanism. The $\mathrm{Ba}+\mathrm{O}_{2}$ reaction was chosen as an example. Ground state barium reacts through a long lived complex. Turning on chemiluminescence of the product $\mathrm{BaO}$ by exciting barium to the $6 s 5 d^{1} D_{2}$ level lets the reaction go through the same mechanism, at least if the collision energy is smaller than $0.6 \mathrm{eV}$. In contrast, the reaction mechanism changes when the chemiluminescence is induced by exciting barium to the $6 s 6 p^{1} P_{1}$ level.

Finally, it was shown that large van der Waals clusters of $\mathrm{N}_{2} \mathrm{O}, \mathrm{CO}_{2}$ and $\mathrm{H}_{2} \mathrm{O}$ do not induce measurable reactive and non reactive luminescent processes when colliding $\mathrm{Ba}\left(6 s^{2}{ }^{1} S_{0}, 6 s 6 p^{1} P^{1}\right)$ atoms. This was interpreted in terms of collisional formation of heavy solvated compounds.

\section{Acknowledgement}

The authors gratefully acknowledge A. Bell (Department of Chemistry, Univ. Southampton, UK) for help in the experimental work.

\section{References}

1. M. R. Levy, Prog. React. Kinet. 10, 1 (1979). (extensive review).

2. D. Husain and G. Roberts, in Advances in Gas-Phase Photochemistry and Kinetics. Bimolecular collisions. M. N. R. Ashfold and J. E. Baggott editors, The Royal Society of Chemistry, London 1989, p. 263, and references therein. 
3. D. Golomb, R. E. Good and R. F. Brown, J. Chem. Phys. 52, 1545 (1970).

4. J. P. Visticot, P. Meynadier, J. Cuvellier, A. Binet and J. M. Mestdagh, Laser Chem. 10, 17 (1989).

5. J. Cuvellier, P. de Pujo, J. M. Mestdagh, J. P. Visticot, J. Berlande and A. Binet, J. Chem. Phys. 90, 7050 (1989).

6. C. Alcaraz, J. M. Mestdagh, P. Meynadier, P. de Pujo, J. P. Visticot, A. Binet and J. Cuvellier, Chem. Phys. Lett. 156, 191 (1989).

7. J. M. Mestdagh, P. Meymadier, P. de Pujo, O. Sublemontier, J. P. Visticot, C. Alcaraz, J. Berlande and J. Cuvellier, Chem. Phys. Lett. 164, 5 (1989).

8. A. Gonzalez Urena, R. B. Bernstein and G. R. Phillips, J. Chem. Phys. 62, 1818 (1975).

9. D. J. Wren and M. Menzinger, Chem. Phys. 66, 85 (1982).

10. J. Nieman and R. Naaman, Chem. Phys. 90, 407 (1984).

11. J. Nieman, J. Schwartz and R. Naaman Z. Phys. D 1, 231 (1986).

12. J. P. Visticot, J. M. Mestdagh, C. Alcaraz, J. Cuvellier and J. Berlande, J. Chem. Phys. 88, 3081 (1988).

13. J. Cuvellier, J. M. Mestdagh, J. Berlande, P. de Pujo and A. Binet, Revue de Phys. Appl. 16, 679 (1981).

J.M. Mestdagh, J. Berlande, J. Cuvellier, P. de Pujo and A. Binet, J. Phys. B. 15, 439 (1982).

14. C. Alcaraz, P. de Pujo, J. Cuvellier and J.M. Mestdagh J. Chem. Phys. 89, 1945 (1988).

15. J. M. Mestdagh, P. de Pujo, J. Pascale, J. Cuvellier and J. Berlande, Phys. Rev. A. 35, 1043 (1987).

16. J. M. Mestdagh, B. A. Balko, M. H. Covinsky, P. S. Weiss, M. F. Vernon, H. Schmidt and Y.T. Lee Faraday Disc. Chem. Soc. 84, 145 (1987).

17. P. S. Weiss, J. M. Mestdagh, M. H. Covinsky, B. A. Balko and Y. T. Lee, Chem. Phys. 126, 93 (1988).

18. H. Schmidt, P. S. Weiss, J. M. Mestdagh, M. H. Covinsky and Y. T. Lee, Chem. Phys. Lett. 118, 539 (1985).

19. D. Paillard, J. M. Mestdagh, J. Cuvellier, P. de Pujo and J. Berlande, J. Chem. Phys. 87, 2084 (1987). J. M. Mestdagh, D. Paillard and J. Berlande, J. Chem. Phys. 88, 2398 (1988).

D. Paillard and J. M. Mestdagh, J. Chem. Phys. 91, 6866 (1989).

20. J. M. L'Hermite, G. Rahmat and R. Vetter, J. Chem. Phys. In press (1990).

21. C. T. Rettner and R. N. Zare, J. Chem. Phys. 77, 2416 (1982).

22. G. Herzberg, Molecular Spectra and Molecular Structure, III, Van Nostrand Reinhold Comp., 1966.

23. Bauschlicher et al., J. Chem. Phys. 84, 901 (1986).

24. H. F. Davis, A. G. Suits, Y. T. Lee, C. Alcaraz and J. M. Mestdagh. To be published.

25. The barium beam was reacted with water and methanol inside the free expansion zone of a jet that was substituted to the molecular beam. The advantage is to increase the density of reactant. The disadvantage is that the collision energy is not as well defined as under the true crossed beam geometry. Under the beam-jet configuration, it was estimated to be about $0.1 \mathrm{eV}$.

26. C. R. Brazier, L. C. Ellingboe, S. Kinsey-Nielsen and P. F. Bernath, J. Am. Chem. Soc. 108, 2126 (1986).

27. A. Schultz, H. W. Cruse and R. N. Zare, J. Chem. Phys. 57, 1354 (1972).

28. P. J. Dagdigian, H. W. Cruse, A. Schultz and R. N. Zare, J.Chem. Phys. 61, 4450 (1974).

29. T. P. Parr, A. Freedman, R. Behrens and R. R. Herm, J. Chem. Phys. 72, 5163 (1980).

30. Proceedings of the Faraday Symposium No 25, "Large Gas Phase Clusters", Birmingham, 1989, J. Chem. Soc. Faraday. Trans. vol. 86 (1990).

31. J. Cuvellier and A. Binet, Revue Phys. Appl. 23, 91 (1988).

32. M. Knapp, O. Echt, D. Kreisle, T. D. Maerk and E. Recknagel, Chem. Phys. Lett, 126, 225 (1986). 